\title{
Impact of demonetization on Indian healthcare system
}

\section{Demonetization drive in India}

Last year, the Indian government announced a demonetization drive for two major notes of its currency-INR 500 and INR 1000. Existing notes of 500 and 1000 denominations were suddenly cancelled from midnight of 9th November, 2016. ${ }^{1}$ It was believed that notes of these two denominations accounted for $>85 \%$ of total circulated cash in the country. ${ }^{2}$ This also meant that during the demonetization drive $>85 \%$ of the circulating money supply needed to be cycled through banks as the money in the form of newly designed notes need to be redeemed within 50days, either by exchange or by depositing the money into bank accounts. Following the announcement, there was a rush at banks and cash vending machines to exchange old notes. A majority of cash vending machines remained shut because of under-supply of new notes.

Even after 30days of the announcement, neither banks had enough of the newly designed currency, nor was there an adequate supply of smaller denominations in the circulation to run the cash economy. ${ }^{3}$ The combined unexpected urgency of not having larger denominations of legal tender, along with a shortfall of smaller denomination currency resulted in massive effect on day-to-day lives of Indian citizens. The demonetization drive had negatively affected India's informal economy as people in lower economic strata of the society surviving on daily wages.

\section{Implications on healthcare}

Appropriate steps were initially taken to avoid inconvenience to the public for first 16days by allowing older high denomination notes at several government outlets, including government run hospitals and pharmacies ${ }^{4}$ Even after weeks following demonetization, several reports highlighted health serviced allegedly being denied to patients with old currency. 5,6 Since majority of patients in India seek medical care in private sector clinics or hospitals, the rejection of healthcare services resulted in unavoidable sufferings and trauma. In addition, a high proportion of India's rural, tribal and migrant population did not had access to any means of electronic money to aid during demonetization drive. $^{7}$

Not only patients, even hospitals and pharmacies were facing the cash-crunch. ${ }^{8}$ On human grounds, some large-scale private hospitals operated their outpatient clinics for initial fewdays. ${ }^{9}$ But that was not the case for small clinics as most of them had no means of accepting electronic mode of payment. Also, independent, private practitioners too faced low patient turnover during the initial days of demonetization. Mainly because they largely preferred physical currency towards their payment, but also because most of the customers haven't turned up for minor health issues in order to save the smaller denomination notes they already had. Similarly, pharmacies accepting old notes since the demonetization was imposed soon started to face problems. As more and more people turned to pharmacies knowing that older denominations are being accepted, the pharmacies soon faced lack of smaller denomination currency and started turning down the customers. Most of the pharmacies remained closed during the initial days of demonetization.
Volume 6 Issue 3 - 2017

\author{
Ram Kumar Mishra \\ Department of Epidemiology, Birla Institute of Technology and \\ Science, India
}

Correspondence: Ram Kumar Mishra, Epidemiology and HEOR, LSBPS-A\&I, Tata Consultancy Services (TCS), Lexington, 5th floor, Thane, Maharashtra, 400607, India, Tel 7770026095, Email mishra.ram@tcs.com

Received: June 14, 2017| Published: August 28, 2017

In recent years, India had emerged as a hub for medical tourism. Every year, thousands of people from developed countries fly over to exotic locations in India to avail medical treatment and exciting holidays. These medical tourists also faced problems as the hospitals refused to accept the old currency initially. Being a foreign national, not having an Indian bank account was a major problem for them. Also, most of them found it inconvenient to stand in long queues along with local crowd.

\section{Long term impact of demonetization}

Since majority of the healthcare expenditure in India is out of pocket spending, a major part of it is spent in cash, and largely in the form of notes of higher denomination. Measures like introduction of cash vending machines at hospital kiosks and registration counters, and increased cash withdrawal limit were helpful for those who are still dependent on cash to avail healthcare. In subsequent month's postdemonetization, Indian government incorporated Aadhaar enabled payment system, through which money can be sent or retrieved using mobile SMS. Similarly, increased penetration of app based third party wallet payment systems has also helped people to make transactions for daily needs.

Alternatively, linking healthcare delivery with biometric enabled Aadhaar card will help to create a central database of the patient's health in the long run. This will not only be helpful to identify disease trends, but will also present a chance to analyze the overall scenario and to come up with appropriate strategy well ahead in time. Health insurance in India primarily focuses on inpatient needs. According to a recent announcement, less than $20 \%$ of the Indian urban population is covered under health insurance..$^{10}$ On the other side, most of the rural population is still not availing any type of health insurance, introduction of a robust government backed health insurance policy with hospital transport coverage for inpatient population might be beneficial. Additionally, encouraging private insurance providers to come-up with adequately-priced schemes might also improve insurance penetration in Indian population. Steady growth of India's health insurance segment ${ }^{11}$ in recent past indicates that people are 
slowly realizing the benefits of insuring their family members to cater unforeseen medical emergencies. Since most of the insurance providers offer cashless hospitalization, there will be no involvement of physical currency.

Since decades, lack of a central patient database is a big concern for Indian healthcare sector. Like other industries, Indian healthcare sector is undergoing a rapid digital transformation, and unbiased claims data is now seen as a critical forecasting tool to prepare stakeholders for shifting market forces. Increasing insurance penetration in India might lead to increased availability of claims data and electronic medical records (EMR). Advantages of leveraging claims data and EMRs include claims data or EMRs can be used as real world evidence providing insights to develop better therapies; enable stakeholders to identify disease trends to take informed decisions to tackle unforeseen outbreaks; and increased availability of structured data can also help policymakers to identify and promote efficient, yet cost effective therapies, which might help to decrease financial burden on the payer. Demonetization bought a short-term chaos, but the situation improved with the supply of new currency over times. The healthcare providers and patients are slowly shifting to alternate mode of transactions. With increasing awareness of digital trends and deeper internet penetration, India is soon going to witness a massive overhaul of healthcare system.

Disclaimer: The opinions expressed in this article are the author's own and do not reflect the view of the organization to which he is affiliated.

\section{Acknowledgements}

None.

\section{Conflict of interest}

Author declares that there is no conflict of interest.

\section{References}

1. Alpana Killawala. Withdrawal of Legal Tender Status for 500 and 1000 Notes: RBI Notice. India; 2016.

2. Raghuram G Rajan. Reserve Bank of India Annual Report 2015-2016. India; 2017. p. 1-198.

3. Shepard W. One Month In, What's The Impact Of India's Demonetization Fiasco? India; 2016.

4. Ministry of Finance. 2016.

5. Sahni I. Pvt hospitals in Gurgaon reject 'illegal' currency. India: Hindustan Times; 2016.

6. Shetty D. Hospitals and drug stores refuse services. India: DNA; 2016.

7. Nagarajan $\mathrm{K}$. India's demonetisation drive is affecting access to medical care. Lancet. 2017;389(10064):32-33.

8. Vora P. No one thinks of the poor: Low-income patients are hobbled by the currency-note ban. Scroll. 2016.

9. Ranchi hospital offers free treatment post demonetization. Business standard. India; 2016.

10. $18 \%$ population of urban area covered under health insurance: Government. India: The Economic Times; 2016.

11. Balachandar G. Health insurance market maintained double digit growth last fiscal year. India: The Hindu; 2016. 